\title{
PENGEMBANGAN MULTIMEDIA INTERAKTIF MOBAWI UNTUK MENGENALKAN MOTIF BATIK NGAWI DI SEKOLAH DASAR
}

\section{Firda Rosita, Hasan Mahfud dan Dwi Yuniasih Saputri}

Universitas Sebelas Maret (UNS) Surakarta Jawa Tengah, Indonesia

Email: frosita721@gmail.com, hasanmahfud@staff.uns.ac.id dan dwiyuniasih@gmail.com

\begin{abstract}
This study is aimed to develop instructional media in introducing batik motifs for elementary school students. The developed earning media is interactive multimedia through a development model with three stages, they are namely defining, designing and development. This study obtained data through group discussion forums from the teachers and principals of Pitu 3 Ngawi Elementary School in solving problems on the field and analyzing learning media needs, doing interview, and documentations. This assessment uses a questionnaire to media experts getting a percentage of $81.11 \%$, material experts $85.33 \%$, and practicing experts $96.84 \%$. The limited trial assessment of Pitu 3 Ngawi Elememtary School students got a percentage of $86.2 \%$, so the interactive multimedia MOBAWI got a good category to be used in introducing Ngawi batik motifs. MOBAWI interactive multimedia can be accepted by students and teachers as the learning media needed in introducing batik and is effective in assisting the learning process of cultural arts and crafts.
\end{abstract}

Keywords: multimedia interaktif; MOBAWI; batik craftsmen

\section{Abstrak}

Penelitian ini bertujuan untuk mengembangkan media pembelajaran dalam mengenalkan motif batik kepada siswa jenjang sekolah dasar. Media Pembelajaran yang dikembangkan yaitu multimedia interaktif melalui metode pengembangan dengan tiga tahap yaitu pendefinisian, perancangan dan pengembangan. Penelitian ini memperoleh data melalui forum group discussion melalui guru dan kepala Sekolah Dasar Negeri (SDN) Pitu 3 Ngawi dalam memperoleh permasalahan di lapangan dan menganalisa kebutuhan media pembelajaran, wawancara dan dokumentasi. Penilaian ini menggunakan angket kepada ahli media memperoleh persentase $81,11 \%$, ahli materi $85,33 \%$, dan ahli praktisi $96,84 \%$. Penilaian uji coba terbatas siswa SDN Pitu 3 Ngawi mendapatkan persentase 86,2\%, sehingga multimedia interaktif Motif Batik Ngawi (MOBAWI) mendapatkan kategori baik untuk digunakan dalam mengenalkan motif batik Ngawi. Multimedia interaktif MOBAWI dapat diterima oleh siswa dan guru sebagai media pembelajaran yang dibutuhkan dalam mengenalkan batik dan efektif dalam membantu proses pembelajaran seni budaya dan prakarya.

Kata Kunci: multimedia interaktif; MOBAWI; motif batik ngawi

$\begin{array}{ll}\text { How to cite: } & \text { Rosita, Firda., Hasan Mahfud dan Dwi Yuniasih Saputri (2021) Pengembangan Multimedia Interaktif } \\ & \text { Mobawi untuk Mengenalkan Motif Batik Ngawi di Sekolah Dasar. Syntax Literate. 6(5). } \\ & \text { http://dx.doi.org/10.36418/syntax-literate.v6i5.2717 } \\ \text { E-ISSN: } & 2548-1398 \\ \text { Published by: } & \text { Ridwan Institute }\end{array}$




\section{Pendahuluan}

Indonesia adalah negara yang mempunyai keragaman yang terdiri dari sosial, budaya, agama dan suku. Salah satu keragaman di Indonesia yang patut dilestarikan adalah budaya. Budhayah merupakan bentuk jamak dari budi yang mempunyai arti akal. Sehingga definisi dari budaya yaitu benda yang digunakan serta diciptakan oleh manusia yang mempunyai tujuan dalam membantu melangsungkan kehidupan bermasyarakat (Kemendikbud, 2016). Budaya dapat didefinisikan secara luas yang terdiri dari kepercayaan, kesenian, dan adat istiadat. Sehingga budaya setiap daerah di Indonesia memiliki perbedaan disebabkan adanya corak latar belakang dari setiap daerah yang menjadi identitas buaya daerah tersebut. Adanya perkembangan teknologi dan ilmu pengetahan merupakan bagian tantangan dari masyarakat untuk tetap menjunjung tinggi budaya daerahnya agar tetap eksistensi di era globalisasi.

Tradisi budaya yang turun-temurun dari leluhur yang patut dilestarikan oleh masyarakat. Salah satu budaya yang terkenal hingga mancanegara adalah batik. Batik merupakan bentuk ekspresi menyampaikan pesan melalui motif yang terdapat pada kain (Nurcahyanti, Sachari \& Destiarmand, 2020). Motif yang terkandung pada kain batik memiliki ciri khusus setiap daerah, misalnya di Pulau Jawa yang mengandung nasehat dan cerita. Makna yang terkandung pada motif batik melambangkan simbol pada setiap daerah. Dapat disebut dengan batik apabila mengandung unsur yaitu dilekatkan menggunakan lilin melalui canting atau alat lain serta mengikuti pola yang membentuk sebuah motif (Mulyanto \& Hartono, 2018).

UNESCO mengakui bahwa batik sebagai warisan budaya, sehingga pada tanggal 2 Oktober diperingati sebagai hari batik nasional di Indonesia (Ningsih, 2015). Hal ini berdampak pada batik Indonesia diminati oleh semua kalangan, termasuk ekspor batik yang mulai naik ke luar negeri. Motif batik yang sering digemari oleh masyarakat yaitu batik Jogjakarta, Pekalongan, dan Surakarta. Sedangkan, di Pulau Jawa setiap daerah memiliki motif yang khas dan belum tereksplore, salah satunya adalah di Provinsi Jawa Timur yang terdapat pada Kabupaten Ngawi.

Eksistensi batik Ngawi belum dikenal oleh masyarakat Ngawi khususnya di siswa sekolah dasar. Bahkan masyarakat Ngawi baru menyadari bahwa Ngawi memiliki batik dengan motif yang beragam. Berdasarkan wawancara yang dilakukan pada kepala sekolah dan guru SDN Pitu 3 Ngawi yang dikumpulkan melalui forum group discussions. Ditemukan fakta bahwa materi di sekolah dasar terdapat kompetensi dasar seni budaya dan prakarya untuk mengenalkan seni rupa daerah yaitu batik. Faktor yang mempengaruhi bahwa siswa belum mengenal motif batik Ngawi melalui pembelajaran disebabkan guru Sekolah Dasar belum memperkenalkan motif yang terkandung dalam batik Ngawi. Guru hanya mengajarkan motif batik sesuai dengan buku siswa tanpa mengeksplor lebih luas. Selain itu juga, seragam yang digunakan oleh siswa dan guru menggunakan motif batik dari daerah lain. Guru mengalami kendala dalam mengajarkan kepada siswa, sehingga guru membutuhkan media dalam memperkenalkan motif batik Ngawi kepada siswa melalui materi pembelajaran. Media dalam memperkenalkan motif batik Ngawi berupa gabungan dari materi, gambar dan video. Akan tetapi guru memiliki 
keterbatasan IT, sehingga guru belum dapat menggunakan media dalam mengajarkan motif batik Ngawi kepada siswa.

Materi mengenai kebudayaan batik terdapat pada muatan lokal yaitu seni budaya dan prakarya di sekolah dasar. Hal ini dilakukan agar siswa tetap melestarikan budaya lokal di era globalisasi. Pendidikan mempunyai peranan penting salah satunya yaitu membentuk generasi bangsa yang bermartabat dan mengenal budayanya, serta mengembangkan potensi yang dimiliki oleh siswa (Puspitorini et al., 2014). Perubahan ilmu pengetahuan dan teknologi mempunyai dampak bagi pendidikan di Indonesia. Salah satunya dampak pada ilmu pengetahuan dalam pendidikan adalah inovasi pada kurikulum 2013. Inovasi yang dibutuhkan salah satunya media pembelajaran yang mempunyai peranan terpenting dalam membantu dan memberikan fasilitas bagi guru dalam memberikan materi ke siswa (Abdulah et al., 2020). Media pembelajaran sangat bermanfaat untuk diterapkan dalam pembelajaran sehingga memberikan keuntungan bagi guru agar terbantu dalam menyampaikan materi (Wardika, 2020). Jenis-jenis media pembelajaran yang dapat digunakan diantaranya gambar, audio dan video. Hal ini sesuai dengan penjelasan yang diberikan oleh guru dalam forum group discussion, sehingga penelitian ini mengembangkan produk media pembelajaran yang memuat materi batik, gambar dan video yang disebut dengan multimedia interaktif.

Multimedia interaktif adalah media yang sangat kompleks dengan mengghadirkan semua unsur yaitu suara, video, animasi yang bertujuan membentuk siswa berpikir kritis dalam memahami materi (Mitchem et al., 2009). Kebermanfaatan dari multimedia interaktif yaitu mampu mengefektifkan pemahaman siswa terhadap materi yang disajikan. Dikatakan efektif mempunyai maksud bahwa siswa dapat menerima dan memahami materi yang telah dipelajari. Sehingga media pembelajaran dapat dikatakan efektif, ketika siswa mampu termotivasi dan mendapatkan hasil maksimal dari materi yang diajarkan dengan menggunakan media pembelajaran (Ab. Rahman et al., 2018).

Hasil penelitian (Manurung \& Panggabean, 2020) mengungkapkan bahwa penggunaan multimedia interaktif dapat menyelesaikan permasalahan yang terjadi pada permasalahan fisika dibanding dengan menggunakan metode konvensional. Penelitian oleh (Sunarti \& Wardani, 2016) mengungkapkan bahwa pengembangan bank soal dan pembahasan ujian nasional berbasis multimedia interaktif melalui macromedia authorware 7.0 mampu memecahkan masalah dalam membantu siswa mempersiapkan ujian nasional. Penelitian oleh (Sholihah et al., 2020) menjelaskan bahwa multimedia interaktif layak digunakan untuk membentuk dan memperkuat karakter siswa yang dapat diterapkan dalam lingkungan. Penelitian (Nandi, 2016) menjelaskan penggunaan multimedia interaktif dapat meningkatkan siswa dalam mempelajari pembelajaran geografi serta mampu meningkatkan kualitas pembelajaran saat penggunaan media pembelajaran tersebut.

Uraian permasalahan di atas dapat ditarik sebuah tujuan penelitian yaitu untuk mengembangkan multimedia interaktif mengenai motif batik di Ngawi yang praktis dan valid dalam penggunaan pembelajaran. Pada uraian tujuan tersebut telah dirumuskan, maka peneliti tertarik melakukan penelitian Research and Development dengan judul 
"Pengembangan multimedia interactive MOBAWI untuk mengenalkan motif batik Ngawi di sekolah dasar"

\section{Metode Penelitian}

Penelitian ini mengembangkan produk yaitu multimedia interaktif dalam mengenalkan motif batik Ngawi. Penelitian ini menggunakan jenis penelitian Research and Development yaitu penelitian yang menghasilkan suatu produk yang telah dirancang dan dibutuhkan sebagai luaran dalam hasil akhir pada penelitian (Sugiyono, 2015). Selain itu juga menggunakan metode penelitian yaitu deskriptif kualitatif dalam mendeskripsikan hasil penelitian. Lokasi penelitian yang digunakan yaitu SDN Pitu 3 Ngawi, yang terletak di Jalan Raya Pitu, Pelemsili, Pitu, Kabupaten Ngawi, Jawa Timur. Teknik pengambilan subjek penelitian menggunakan teknik purposive sampling.

Teknik pengambilan data yang digunakan melalui forum group discussion dengan menggunakan pertanyaan terbuka sesuai dengan pedoman wawancara, angket, dan dokumentasi. Pengambilan data untuk angket digunakan dalam menilai produk pengembangan multimedia interaktif yang digunakan oleh validasi ahli media, ahli materi, ahli praktisi, dan uji coba terbatas. Dalam mengukur teknik uji validitas data menggunakan teknik triangulasi. Subjek penelitian yang digunakan adalah siswa kelas V SDN Pitu 3 Ngawi yang berjumlah 10. Penelitian ini menggunakan teknik analisis data yaitu pengumpulan data, penyajian data, menampilkan data dan penyimpulan data (Miles \& Huberman, 1994: 14). Skor pada angket dapat dideskripsikan melalui skala likert yang dapat dihubungkan menggunakan kalimat deksriptif. Tahapan analisis data menggunakan angket sebagai data kuantitatif yang akan digunakan dalam metode statistik deskriptif kualitatif. Sehingga, dalam menghitung skor angket menggunakan rumus (Azhar, 2013: 33) yaitu:

$$
\mathrm{M}=a \frac{\Sigma f x}{N}
$$

Keterangan:

$\mathrm{M}=$ Skor rata-rata dari data yang digunakan

$\Sigma f x=$ Jumlah skor dari data

$N=$ Jumlah seluruh komponen yang digunakan

Selanjutnya, setelah menghitung rata-rata keseluruhan, maka melaksanakan tahapan yaitu mencocokkan dengan kriteria interval yang dihubungkan pada kategori penilaian. Sehingga dapat ditarik sebuah kesimpulan terhadap data tersebut.

Tabel 1

\begin{tabular}{cc} 
Kriteria Penilaian Terhadap Multimedia Interaktif \\
\hline Kategori Penilaian & Skor \\
\hline Sangat Baik & 5 \\
\hline Baik & 4 \\
\hline Cukup Baik & 3 \\
\hline Kurang baik & 2 \\
\hline Tidak Baik & 1 \\
\hline
\end{tabular}


Penelitian pengembangan multimedia interaktif "MOBAWI" menggunakan desain 4D yang diadaptasi dari (Thiagarajan \& Lawhon, 1976) akan tetapi pada penelitian ini hanya sampai pada tahap 3D. Tahapan prosedur pengembangan produk multimedia interaktif mengenal motif batik Ngawi yaitu tahap pendefinisian, perancangan dan pengembangan.

\section{Hasil dan Pembahasan}

\section{A. Hasil Penelitian}

\section{Tahap Pendefinisian}

Tujuan menganalisa permasalahan yang terjadi di lapangan dan mengetahui kebutuhan yang diperlukan oleh subjek penelitian. Tahapan pendefinisian pada penelitian ini menggunakan studi pendahuluan yaitu forum group discussion untuk mengetahui permasalahan yang terjadi mengenai kurangnya pemahaman dan pengenalan motif batik Ngawi di sekolah dasar, media yang telah digunakan sebelumnya, serta menganalisa kebutuhan media pembelajaran yang dibutuhkan dalam mengenalkan batik Ngawi. Pertanyaan yang diajukan dalam forum group discussion yaitu : 1) pengetahuan guru mengenai motif batik Ngawi; 2) pentingnya mengenalkan motif batik kepada siswa khususnya kelas 5 di jenjang sekolah dasar terkait adanya kompetensi dasar di mata pelajaran seni budaya dan prakarya dalam mengenalkan seni rupa daerah; 3 ) cara guru dalam mengenalkan serta mengajarkan motif batik Ngawi kepada siswa; 4) media pembelajaran yang sebelumnya digunakan; 5) gambaran media pembelajaran yang dibutuhkan; 6) konten yang dibutuhkan dalam media pembelajaran.

Hasil yang diperoleh dalam forum group discussion yaitu bahwa guru telah mengetahui motif batik Ngawi, akan tetapi guru belum mengenalkan kepada siswa disebabkan guru hanya terfokus pada pengenalan batik secara umum yang terdapat pada buku siswa, guru SDN Pitu 3 Ngawi mengungkapkan bahwa pentingnya mengajarkan batik kepada siswa sedini mungkin agar dapat ikut serta melestarikan budaya khas Ngawi. Penyebab guru belum mengenalkan batik Ngawi yaitu guru membutuhkan media pembelajaran yang dapat menarik antusiasme siswa untuk belajar mengenal batik Ngawi. Sebelumnya, guru hanya menggunakan media pembelajaran berupa power point dalam pembelajaran. Konten power point yang ditampilkan guru kepada siswa sama dengan yang ada di buku siswa, karena guru hanya copy-paste dari buku siswa yang dipindahkan dalam power point. Guru jarang menggunakan media pembelajaran dikarenakan keterbatasan guru dalam membuat dan mengoperasikan media pembelajaran. Guru mengungkapkan bahwa guru sering menggunakan metode konvensional dalam mengajar.

\section{Tahap Perancangan}

Hasil forum group discussion yang dilaksanakan oleh guru SDN Pitu 3 Ngawi, bahwa guru membutuhkan media pembelajaran yang berisikan materi, 
gambar, animasi, serta video. Peneliti menyimpulkan komponen yang dibutuhkan oleh guru dalam membuat media pembelajaran yaitu terdapat dalam karakteristik multimedia interaktif untuk mengenalkan motif batik Ngawi. Selanjutnya, penelitian ini dilanjutkan yaitu pada tahapan rancangan. Prototype produk pada media pembelajaran dalam mengenalkan motif batik Ngawi dalam membuat multimedia interaktif yaitu Smart App Creator. Sebelum membuat produk pengembangan multimedia interaktif, peneliti melakukan wawancara terhadap pengrajin batik Ngawi untuk memperoleh motif pokok batik Ngawi. Hasil wawancara yang diperoleh dari pengrajin batik Ngawi yaitu ditemukan bahwa Kabupaten Ngawi memiliki 5 motif pokok yaitu motif kali tempuk, motif benteng pendhem, motif padi, motif bambu, dan motif manusia purba. Selain itu juga dalam memperoleh materi, peneliti menggunakan studi dokumentasi berupa foto motif batik Ngawi dan teknik pembuatan batik Ngawi yang digunakan sebagai konten dalam rancangan multimedia interaktif.

Tahap pembuatan multimedia interaktif dalam mengenalkan motif batik Ngawi yaitu pembuatan desain media, penyusunan materi yang dibutuhkan oleh guru untuk siswa, dan mengubah multimedia interaktif ke dalam aplikasi. Pembuatan desain media membutuhkan background yang bertemakan batik secara umum, animasi serta warna yang mampu menarik siswa dalam belajar, dan tombol navigasi yang menghubungkan materi ke materi berikutnya. Penyusunan materi yang dibutuhkan oleh guru untuk siswa. Bagian menu pada materi terdapat pilihan materi yang akan dipelajari yaitu pengertian batik secara umum, 5 motif pokok Kabupaten Ngawi, makna motif batik Ngawi, alat dan bahan yang digunakan dalam membatik, teknik pembuatan batik, dan quiz sebagai soal evaluasi.
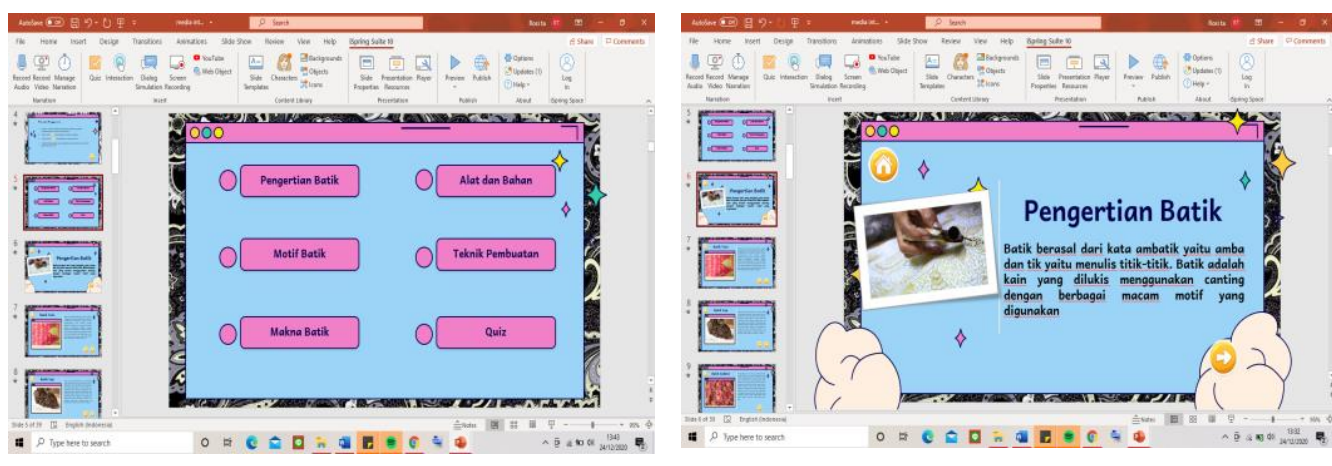

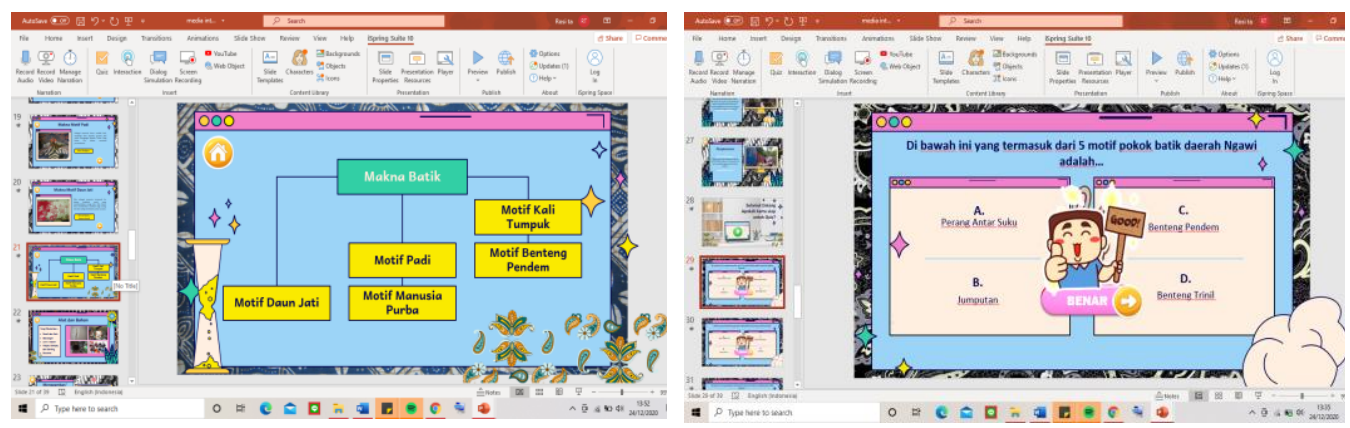

Gambar 1

Rancangan Pengembangan Multimedia Interaktif

\section{Tahap Pengembangan}

Pengembangan produk multimedia interaktif dalam mengenalkan motif batik Ngawi sesuai dengan kriteria yang diinginkan oleh guru. Setelah melalui tahap perancangan selanjutnya yaitu membentuk aplikasi dari prototype yang telah dibuat. Langkah selanjutnya yaitu melaksanakan uji kelayakan pengembangan produk multimedia interaktif dalam mengenalkan motif batik Ngawi terhadap validasi ahli media, ahli materi, dan ahli praktisi.

Pelaksanaan uji kelayakan pada ahli media terhadap produk pengembangan multimedia interaktif berbasis aplikasi dalam mengenalkan motif batik Ngawi. Indikator angket penilain ahli media yaitu tampilan dan penggunaan. Indikator tampilan terdiri dari komponen tampilan, gambar, audio dan video. Indikator penggunaan yang digunakan pada aspek penggunaan yaitu pengguna dan kemasan materi. Komponen pengguna terdiri dari kesesuaian dengan sasaran pengguna, media yang fleksibel digunakan kapan dan dimana saja, dan mampu digunakan secara online maupun offline. Aspek kedua adalah kemasan materi yang terdiri dari kesesuaian materi yang disajikan sesuai dengan kebutuhan guru dan siswa, kesesuaian penggunaan tombol penunjuk dalam menghubungkan materi, dan materi yang disajikan actual.

\section{Tabel 2}

Penilaian Ahli Media Terhadap Multimedia Interaktif MOBAWI

\begin{tabular}{ccccc}
\hline No & $\begin{array}{c}\text { Indikator } \\
\text { Penilaian }\end{array}$ & $\begin{array}{c}\text { Skor } \\
\text { diperoleh }\end{array}$ & $\begin{array}{c}\text { Skor } \\
\text { diharapkan }\end{array}$ & Persentase \\
\hline 1 & Tampilan & 47 & 60 & $78,33 \%$ \\
\hline 2 & Penggunaaan & 26 & 30 & $86,67 \%$ \\
\hline & Total & 73 & 90 & $81,11 \%$ \\
\hline
\end{tabular}

Penilaian yang diberikan oleh ahli media terhadap Multimedia Interaktif MOBAWI dapat diketahui bahwa hasil yang diberikan oleh ahli media yaitu 73 dengan persentase $81,11 \%$. Saran yang diberikan oleh ahli media terhadap produk pengembangan yaitu: (1) penggunaan ukuran font yang diperbesar serta jenis font yang digunakan pada multimedia interaktif diubah ke dalam andika new basic; (2) 
penambahan tujuan pembelajaran unsur degree yang dicantumkan dalam multimedia interaktif; 3) penggunaan kalimat pada petunjuk penggunaan agar lebih singkat, padat dan jelas; 4) petunjuk simbol yang digunakan agar lebih konsisten dalam segi warna dan penambahan kejelasan keterangan pada tombol yang terdapat pada multimedia interaktif; 5) penambahan tanda baca berupa titik dalam setiap akhir kalimat; 6) perbaikan kosakata agar lebih tepat sesuai sasaran penggunaan yaitu pada jenjang sekolah dasar khususnya kelas $\mathrm{V}$; 7) penggabungan menu antara alat dan bahan serta teknik pembuatan agar materi lebih padat; 8) penambahan jumlah pertanyaan pada quiz sebagai soal evaluasi. Hasil dan saran dari ahli media telah diberikan terhadap pengembangan produk multimedia interaktif mengenalkan motif batik Ngawi, dapat disimpulkan dari hasil dan persentase menyebutkan bahwa multimedia interaktif berbasis aplikasi MOBAWI termasuk ke dalam kategori baik yang layak digunakan untuk selanjutnya diujicobakan ke lapangan dengan syarat sesuai saran yang telah diberikan.

Penilaian angket yang diberikan kepada ahli materi terdiri 3 (tiga) aspek indikator yaitu pembuka, isi dan penutup. Aspek pembukaan terdiri dari adanya petunjuk penggunaan, kompetensi dasar serta indikator yang tercantum, menu pada media pembelajaran yang disajikan sesuai dengan materi. Aspek isi terdiri dari keruntutan materi, kejelasan materi, kebenaran materi, pendalaman materi, kemenarikan materi, kesesuaian penyajian contoh, kesesuaian bahasa dengan sasaran pengguna sesuai dengan karakteristik siswa, teks yang digunakan mudah dibaca dan gambar yang disajikan sesuai dengan materi mengenai motif batik Ngawi. Aspek terakhir yaitu penutup terdiri dari kesesuaian quiz sebagai soal evaluasi dengan materi, kualitas umpan balik berupa penguatan positif dan negative, dan proporsi pertanyaan dalam quiz.

Tabel 3

Penilaian Ahli Materi Terhadap Multimedia Interaktif MOBAWI

\begin{tabular}{ccccc}
\hline No & $\begin{array}{c}\text { Indikator } \\
\text { Penilaian }\end{array}$ & $\begin{array}{c}\text { Skor yang } \\
\text { diperoleh }\end{array}$ & $\begin{array}{c}\text { Skor yang } \\
\text { diharapkan }\end{array}$ & Persentase \\
\hline 1 & Pembukaan & 15 & 15 & $100 \%$ \\
\hline 2 & Isi & 35 & 45 & $77,78 \%$ \\
\hline 3 & Penutup & 14 & 75 & $93,33 \%$ \\
\hline & Total & 64 & 75 & $85,33 \%$ \\
\hline
\end{tabular}

Saran yang diberikan oleh ahli materi bahwa materi yang terkandung dalam media pembelajaran yaitu: 1) agar materi mengenai motif batik Ngawi lebih diperjelas dan lebih dipadatkan; 2) bahasa lebih disesuaikan kepada sasaran pengguna yaitu siswa jenjang sekolah dasar khususnya kelas V. Sesuai dengan saran dari pendapat validator ahli materi dapat disimpulkan bahwa materi pada produk pengembangan multimedia interaktif dalam mengenalkan motif batik 
Ngawi yaitu sangat baik maupun sangat layak digunakan untuk diujicobakan ke lapangan kepada siswa.

Tahap pengembangan berikutnya yaitu uji kelayakan terhadap ahli praktisi untuk mengetahui kelayakan produk pengembangan multimedia interaktif MOBAWI. Indikator yang digunakan dalam penilaian angket kepada ahli praktisi yaitu media dan materi. Aspek media yang terdiri dari komponen penggunaan, audio, video, gambar. Pada aspek penggunaan multimedia interaktif sesuai dengan sasaran pengguna, dapat digunakan secara online maupun offline. Indikator materi terdiri dari kejelasan, kebenaran pendalaman, kemenarikan, kesesuaian penyajian contoh, kesesuaian bahasa dengan EYD, kesesuaian soal latihan, umpan balik berupa penguatan positif serta negative terhadap materi motif batik Ngawi pada multimedia interaktif MOBAWI.

Tabel 4

Penilaian Ahli Praktisi Terhadap Multimedia Interaktif MOBAWI

\begin{tabular}{ccccc}
\hline No & Indikator & $\begin{array}{c}\text { Skor yang } \\
\text { diperoleh }\end{array}$ & $\begin{array}{c}\text { Skor yang } \\
\text { diharapkan }\end{array}$ & Persentase \\
\hline 1 & Media & 44 & 45 & $97,77 \%$ \\
\hline 2 & Materi & 48 & 50 & $96 \%$ \\
\hline & Total & 92 & 95 & $96,84 \%$ \\
\hline
\end{tabular}

Penilaian multimedia interaktif yang diberikan oleh ahli praktisi melalui angket mendapatkan kategori sangat baik untuk dilaksanakan uji terbatas kepada siswa kelas V SDN Pitu 3 Ngawi. Hasil uji kelayakan terhadap ahli media, ahli materi dan ahli praktisi dalam bentuk gambar diagram terhadap multimedia interaktif MOBAWI dalam mengenalkan motif batik Ngawi.

Tahap pengembangan yaitu pelaksanaan uji coba terbatas kepada siswa SDN Pitu 3 Ngawi. Sebelum, pelaksanaan uji coba terbatas produk yang dikembangkan melalui tahapan revisi sesuai dari saran dari validator. Subjek yang digunakan adalah siswa yang mengetahui tujuan pada penelitian ini yaitu kelas V dengan jumlah 10 orang. Penilaian yang digunakan yaitu angket yang berjumlah 18 butir pertanyaan mengenai percobaan terhadap multimedia interaktif MOBAWI. Indikator yang digunakan untuk uji coba terbatas kepada siswa kelas V SDN Pitu 3 Ngawi terdiri dari media dan materi. Indikator media terdiri segi penggunaan, gambar, video, video, tampilan. Indikator materi terdiri dari siswa mengetahui tujuan pembelajaran, materi yang mudah dipelajari, kebermanfaatan materi, kemudahan dalam pengerjaan soal evaluasi, materi yang mudah dipahami dan kejelasan contoh motif batik. 


\section{Tabel 5}

Penilaian Uji Coba Terbatas Siswa SDN Pitu 3 Ngawi

\begin{tabular}{cccccc}
\hline No & Indikator & $\begin{array}{c}\text { Jumlah } \\
\text { Siswa }\end{array}$ & $\begin{array}{c}\text { Rata-rata } \\
\text { keseluruhan }\end{array}$ & Persentase & Kategori \\
\hline 1 & $\begin{array}{c}\text { Media dan } \\
\text { Materi }\end{array}$ & 10 & 77,6 & $86,2 \%$ & Baik \\
\hline
\end{tabular}

Berdasarkan penilaian berupa angket yang diberikan oleh siswa untuk uji coba terbatas terhadap pengembangan produk multimedia interaktif MOBAWI mendapatkan rata-rata yaitu 77.6 dan persentase $86.2 \%$, sehingga mendapatkan kategori baik digunakan sebagai media pembelajaran dalam mengenalkan motif batik Ngawi.

\section{B. Pembahasan}

Penelitian pengembangan media pembelajaran yang digunakan adalah multimedia interaktif dalam mengenalkan motif batik Ngawi kepada siswa kelas V SDN Pitu 3 Ngawi. Multimedia interaktif MOBAWI mengembangkan pengetahuan terhadap motif batik Ngawi, makna motif batik hingga teknik pembuatan dalam membatik. Setelah, siswa mengoperasikan multimedia interaktif MOBAWI maka, siswa telah mengetahui adanya motif batik yang dimiliki oleh Kabupaten Ngawi dan dapat diterapkan dalam pembelajaran seni budaya dan prakarya. Model pengembangan yang digunakan adalah 4D yang diadaptasi oleh (Thiagarajan \& Lawhon, 1976) akan tetapi penelitian ini hanya sebatas 3D yaitu tahap define, design, dan development. Model 4D dipilih karena sesuai dengan kriteria dan langkah yang digunakan pada proses pembuatan multimedia interaktif MOBAWI. Penelitian sebelumnya menggunakan multimedia interaktif yang mampu memberikan solusi dari permasalahan yang terjadi di lapangan

Hasil studi pendahuluan menjelaskan bahwa siswa belum mengetahui motif batik Ngawi, disebabkan guru mengalami kesulitan dalam mengenalkan kepada siswa, guru membutuhkan media pembelajaran yang mampu menarik siswa agar antusias untuk mengenal dan melestarikan batik Ngawi. Sebelumnya, guru hanya menggunakan metode ceramah dan power point dalam mengajar. Awal mula penggunaan power point siswa terlihat antusias karena dianggap hal baru dalam pembelajaran, sehingga hasil belajar siswa meningkat (Liu, Xu \& Pange, 2016). Di sisi lain, siswa semakin jenuh karena konten yang digunakan pada power point hanya copy paste dari buku siswa. Sehingga media pembelajaran yang diperlukan oleh guru adalah media yang mengandung materi serta gambar yang berfungsi untuk mengenalkan materi serta jenis-jenis motif yang dimiliki oleh Kabupaten Ngawi. Berdasarkan hasil dari forum group discusision yaitu peneliti mengembangkan media pembelajaran yang diperlukan yaitu multimedia interaktif MOBAWI dalam mengenalkan motif batik Ngawi kepada siswa dianggap efektif daripada menggunakan metode konvensional dalam pembelajaran. 
Tahap perancangan pada pengembangan multimedia interaktif MOBAWI menggunakan software smart app creator untuk mengembangan produk tersebut. Konten yang digunakan pada multimedia interaktif didapatkan melalui wawancara dan observasi terhadap pengrajin batik Ngawi. Sebelum melaksanakan pengembangan multimedia interaktif MOBAWI, peneliti melakukan analisa terhadap kompetemsi dasar yang mengacu pada silabus kurikulum 2013 (Qumillaila, Baiq Hana Susanti, 2017). Setelah, multimedia interaktif dibentuk menjadi sebuah aplikasi dengan tujuan multimedia interaktif dapat digunakan melalui smartphone yang dimiliki oleh siswa, sehingga siswa dapat megguakan kapan dan dimana saja. (Syawaludin, Gunaedi \& Rintayati, 2019). Multimedia interaktif "MOBAWI" dibentuk melalui aplikasi dimaksudkan karena kondisi pandemic sehingga guru tidak dapat menjelaskan secara langsung, sehingga penggunaan aplikasi dianggap sebagai alternatif agar siswa tetap antusias meskipun belajar di rumah.

Tahap pengembangan pada penelitian ini menggunakan uji kelayakan terhadap ahli media, ahli materi dan ahli praktisi. Tujuannya untuk mengukur kelayakan terhadap media pembelajaran yang digunakan. Uji kelayakan terhadap validator menggunakan penilaian angket yang mempunyai fungsi untuk mengolah data yang dibutuhkan (Susilawati, Setiawan \& Khoiri, 2018). Ahli media memberikan nilai 73 kepada pengembangan produk multimedia interaktif "MOBAWI" dengan persentase 81,11\% termasuk ke dalam kategori baik. Ahli materi memerikan nilai 63 dengan persentase $84 \%$ termasuk ke dalam kategori sangat baik. Sedangkan, ahli praktisi memberikan nilai 92 dengan persentase 96, $84 \%$ termasuk kategori sangat baik. Pada uji kelayakan terdapat kritik dan saran terhadap multimedia interaktif MOBAWI untuk diperbaiki sebelum pelaksanaan uji coba terbatas kepada siswa.

Pelaksanaan uji coba terbatas sebagai langkah terakhir dari tahap pengembangan pada model 3D adaptasi Thiagarajan. Pengembangan multimedia interaktif MOBAWI pada tahap uji coba terbatas dilaksanakan di SDN Pitu 3 Ngawi melalui penilaian angket yang dikerjakan oleh 10 siswa. Hasil penelitian ini menunjukkan bahwa siswa tertarik terhadap multimedia interaktif MOBAWI ditunjukkan adanya penilaian angket yang dilaksanakan melalui uji coba terbatas menunjukkan rata-rata keseluruhan yaitu 77.6 dari 10 siswa. Sehingga rata-rata tersebut menujukkan bahwa uji coba terbatas terhadap pengembangan media pembelajaran berupa multimedia interaktif MOBAWI menunjukkan kategori baik dan layak digunakan. Hasil penilaian tersebut menyebutkan bahwa rata-rata siswa menilai dengan kriteria baik hingga sangat baik pada multimedia interaktif MOBAWI untuk digunakan sebagai media pembelajaran dalam mengenal motif batik Ngawi. Pemanfaatan media pembelajaran multimedia interaktif MOBAWI dapat meningkatkan perhatian dan minat dibanding hanya menggunakan media visual maupun metode konvensional yang sering digunakan oleh guru (Sunarti \& Wardani, 2016). 
Seiring berkembangnya waktu, kemajuan terhadap teknologi di era globalisasi ini mempunyai dampak terhadap terhadap pendidikan (Moniaga et al., 2019). Multimedia interaktif MOBAWI mempunyai pengaruh yang sangat penting dalam mengenalkan motif batik yang dibutuhkan dalam kemajuan teknologi pada saat ini. Dengan adanya kemajuan teknologi yang sangat pesat di Abad 21 yang berdampak pada pemanfaatan teknologi termasuk ke dalam dunia pendidikan (Sholihah et al., 2020). Keunggulan adanya era manfaat teknologi yaitu dalam pendidikan dapat mengakses informasi serta terdapat portal pembelajaran yang dapat mudah diakses (Purnami,Mulyoto \& Winoto, 2020). Penggunaan media pembelajaran adalah salah satu adanya manfaat teknologi yang dapat mempengaruhi proses pembelajaran agar mencapai tujuan yang dicapai (Hamid, Yuliawati \& Ariwibowo, 2020). Media pembelajaran dibutuhkan untuk menyampaikan materi sehingga tujuan pembelajaran digunakan dapat efektif dilaksanakan (Saputri, Rukayah \& Indriayu, 2018).

Multimedia interaktif merupakan media yang lengkap karena dalam konten media tersebut terdiri dari gabungan aspek materi, gambar, video, audio dan animasi sehingga siswa dapat memahami materi yang disampaikan secara mandiri (Djamas, Tinedi \& Yohandri, 2018). Pengembangan produk multimedia interaktif berbasis aplikasi, siswa dapat mempelajari dan memahami secara langsung dari tampilan mengenai penjelasan batik, materi batik melalui gambar motif batik Ngawi, video teknik pembuatan dalam membatik, audio dan animasi dalam soal evaluasi ketika siswa menjawab. Sehingga animasi yang digunakan dalam soal evaluasi menambah minat siswa dalam menyelesaikan soal mengenai materi motif batik Ngawi. Multimedia interaktif termasuk inovasi dalam bidang pendidikan khususnya media pembelajaran yang berpengaruh kepada siswa dalam meningkatkan pengaruh yang positif terhadap pembelajaran (Lahwal, Ajlal \& Amain, 2016)

Multimrdia interaktif dipilih agar siswa mempunyai pengalaman yang baru mengenai media pembelajaran pada saat menggunakan dan mengaplikasikannya Media gambar yang disajikan pada multimedia interaktif berupa contoh motif batik pokok dan gambar mengenai alat dan bahan. Media gambar mempunyai fungsi agar siswa memiliki pemikiran yang nyata terhadap materi (Kholilah, Purwaningsih \& Sulaiman, 2020)

Multimedia interaktif MOBAWI menyajikan sebuah video berupa proses pembuatan batik dari tahap menggambar motif, mencanting, memberikan warna, hingga penjemuran sebagai tahap akhir. Tujuan adanya agar siswa dapat melihat secara langsung proses pembuatan batik melalui langkah-langkah yang disajikan melalui video. Efek positif dari penyajian video yaitu dapat meningkatkan keterampilan menyimak pada siswa dan sebagai media yang efektif dalam memberikan materi berupa fakta (Sulaiman et al., 2017). Video dalam sebuah media pembelajaran dapat membuat siswa mengetahui materi secara otentik melalui pembelajaran yang bermakna. Dengan adanya video yang disajikan pada 
multimedia interaktif dapat menyelaraskan pemikiran siswa yang semula abstrak menjadi konkret atau nyata (Hapsari et al., 2019). Sehingga multimedia interaktif MOBAWI dianggap sebagai media pembelajaran yang tepat untuk mengenalkan motif batik Ngawi di Sekolah Dasar.

\section{Kesimpulan}

Berdasarkan hasil penelitian pengembangan produk media pembelajaran dalam mengenal motif batik yaitu multimedia interaktif MOBAWI. Penelitian ini menggunakan model 3D dengan tahapan define, design dan development hingga uji coba terbatas kepada siswa yang berjumlah 10 siswa. Pada tahap define menggunakan forum group discussion untuk memperoleh permasalahan di lapangan. Tahap design yaitu dengan merancang materi batik dan media pembelajaran menggunakan software Smart App Creator. Tahap development pada penelitian ini menggunakan uji kelayakan terhadap ahli media, ahli materi dan ahli praktisi. Berdasarkan hasil penilaian angket oleh ahli media memperoleh persentase $81,11 \%$. Sedangkan, penilaian angket oleh ahli praktisi terhadap multimedia interaktif MOBAWI yaitu 85,33\% dan ahli praktisi memberikan penilaian dengan persentase $96,84 \%$. Selanjutnya, setelah pelaksanaan uji kelayakan terhadap para ahli dan memperbaiki produk agar dapat dilaksanakan uji coba terbatas kepada siswa dengan menggunakan penilaian angket sesuai dengan indikator yang diberikan. Persentase uji coba terbatas yang telah dinilai yaitu memperoleh 86, $2 \%$ dengan kategori baik. Sehingga, multimedia interaktif MOBAWI dikategorikan baik dan layak sebagai media pembelajaran dalam mengenal motif batik Ngawi. Selain mempunyai manfaat dalam mengenalkan motif batik Ngawi, multimedia interaktif MOBAWI mampu meningkatkan motivasi belajar siswa, dan meningkatkan keterampilan berpikir kritis siswa. Multimedia interaktif MOBAWI dibentuk ke-dalam sebuah aplikasi yang dapat diunduh melalui link agar menambah keefektifan selama pembelajaran di masa pandemi. 


\section{BIBLIOGRAFI}

Ab. Rahman, A., Sahrir, M. S. Bin, Zainuddin, N., \& Abd Khafidz, H. (2018). Evaluating Global Zakat Game (GZG) board game in enhancing Zakat education. Journal of Education and Learning (EduLearn), 12(3), 568. Google Scholar

Abdulah, T., Widaningsih, L., \& Minggra, R. (2020). Puzzle game development as a learning media in learning outcomes of building construction basics. IOP Conference Series: Materials Science and Engineering, 830(4). Google Scholar

Djamas, D., Tinedi, V., \& Yohandri. (2018). Development of interactive multimedia learning materials for improving critical thinking skills. International Journal of Information and Communication Technology Education, 14(4), 66-84. Google Scholar

Hamid, M. A., Yuliawati, L., \& Aribowo, D. (2020). Feasibility of Electromechanical Basic Work E-Module As a New Learning Media for Vocational Students. Journal of Education and Learning (EduLearn), 14(2), 199-211. Google Scholar

Hapsari, A. S., Hanif, M., Gunarhadi, \& Roemintoyo. (2019). Motion graphic animation videos to improve the learning outcomes of elementary school students. European Journal of Educational Research, 8(4), 1245-1255. Google Scholar

Kemendikbud. (2016). Analisis Kearifan Lokal Ditinjau dari Keragaman Budaya. In Pusat Data dan Statistik Pendidikan dan Kebudayaan (PDSPK) (pp. 1-67). http://publikasi.data.kemdikbud.go.id/uploadDir/isi_F9B76ECA-FD28-4D62BCAE-E89FEB2D2EDB_.pdf. Google Scholar

Kholilah, K., Purwaningsih, D. I., \& Sulaiman, S. (2020). Analisis Kebutuhan Pengembangan Media Pada Pembelajaran Phonetics. Paedagoria: Jurnal Kajian, Penelitian Dan Pengembangan Kependidikan, 11(2), 202-207. Google Scholar

Lahwal, F., Al-Ajlan, A. S., \& Amain, M. (2016). A proposed framework between internal, external and pedagogy dimensions in adoption of interactive multimedia elearning. Turkish Online Journal of Distance Education, 17(4), 158-174. Google Scholar

Liu, X., Xu, Y., \& Pange, J. (2016). Teachers' use of PowerPoint in kindergarten: An empirical investigation in China. Education and Information Technologies, 21(2), 425-441. https://doi.org/10.1007/s10639-014-9330-z. Google Scholar

Manurung, S. R., \& Panggabean, D. D. (2020). Improving students' thinking ability in physics using interactive multimedia based problem solving. Cakrawala Pendidikan, 39(2), 460-470. https://doi.org/10.21831/cp.v39i2.28205. Google Scholar

Miles, M. B., \& Huberman, M. (1994). Qualitative Data Analysis (Second). SAGE Publication. Google Scholar 
Firda Rosita, Hasan Mahfud dan Dwi Yuniasih Saputri

Mitchem, K., Koury, K., Fitzgerald, G., Hollingsead, C., Miller, K., Tsai, H.-H., \& Shenghua Zha. (2009). The Effects of Instructional Implementation on Learning With Interactive Multimedia Case-Based Instruction. Teacher Education and Special Education: The Journal of the Teacher Education Division of the Council for Exceptional Children, 32(4), 297-318. Google Scholar

Moniaga, J. V., Ohyver, M., Siregar, J., \& Yauwito, P. H. (2019). Map-type modelling and analysis of children stunting case data in Indonesia with interactive multimedia method. Procedia Computer Science, 157, 530-536. https://doi.org/10.1016/j.procs.2019.09.010. Google Scholar

Mulyanto, \& Hartono, L. (2018). 33 Kesenian Reog Sebagai Sumber Ide Pengembangan Desain Motif Batik Ponorogo Reog Art as Source of Ideas for Ponorogo Batik Motif Design Development. Dinamika Kerajinan Dan Batik, 33-44. Google Scholar

Nandi, N. (2016). Penggunaan Multimedia Interaktif Dalam Pembelajaran Geografi Di Persekolahan. Jurnal Geografi Gea, 6(2). Google Scholar

Ningsih, D. N. (2015). Dampak Ekonomi Ekspor Perdagangan Batik Indonesia Ke Amerika Serikat Tahun 2010-2014. Jom FISIP, Vol.2 No.2(2), 6. https://www.neliti.com/publications/32287/dampak-ekonomi-ekspor-perdaganganbatik-indonesia-ke-amerika-serikat-tahun-2010 Google Scholar

Nurcahyanti, D., Sachari, A., \& Destiarmand, A. H. (2020). Peran Kearifan Lokal Masyarakat Jawa Untuk Melestarikan Batik Tradisi di Girilayu, Karanganyar, Indonesia. Mudra Jurnal Seni Budaya, 35(2), 145-153. Google Scholar

Purnami, A. S., Mulyoto, M., \& Winoto, B. (2020). Android-based shopping skill for mentally-disable student. Journal of Education and Learning (EduLearn), 14(3), 411-415. Google Scholar

Puspitorini, R., Prodjosantoso, A. K., Subali, B., \& Jumadi, J. (2014). Penggunaan Media Komik Dalam Pembelajaran Ipa Untuk Meningkatkan Motivasi Dan Hasil Belajar Kognitif Dan Afektif. Jurnal Cakrawala Pendidikan, 3(3), 413-420. Google Scholar

Qumillaila, Baiq Hana Susanti, Z. (2017). Pengembangan Augmented Reality Versi Android Developing Android Augmented Reality As a Learning Media of. Jurnal Cakrawala Pendidikan, 36(1), 57-69. Google Scholar

Saputri, D. Y., Rukayah, R. R., \& Indriayu, M. I. (2018). Integrating Game-based Interactive Media as Instructional Media: Students' Response. Journal of Education and Learning (EduLearn), 12(4), 638. Google Scholar

Sholihah, A. N. N., Septiani, I., Rejekiningsih, T., Triyanto, \& Rusnaini. (2020). Development of interactive multimedia learning courseware to strengthen students' character. European Journal of Educational Research, 9(3), 1267-1279. Google Scholar 
Pengembangan Multimedia Interaktif Mobawi untuk Mengenalkan Motif Batik Ngawi di Sekolah Dasar

Sugiyono. (2015). Metode Penelitian Pendidikan (Penelitian Kualitatif, Kuantitatif, $R \& D)$. Bandung: Alfabeta. Google Scholar

Sulaiman, N., Muhammad, A. M., Ganapathy, N. N. D. F., Khairuddin, Z., \& Othman, S. (2017). A Comparison of Students' Performances Using Audio Only and Video Media Methods. English Language Teaching, 10(7), 210. Google Scholar

Sunarti, S. R., \& Wardani, S. (2016). Sebagai Media Pembelajaran Tematik Siswa Kelas V Sekolah Dasar Sunarti, Selly Rahmawati, dan SetiaWardani Developing A Game Called "Petualangan Si Bolang " As The Thematics Learning Media To Improve The Fifth Grade Students ' Motivation And Learning Ac. Jurnal Cakrawala Pendidikan, 5(1), 58-68. Google Scholar

Susilawati, S., Setiawan, N., \& Khoiri, N. (2018). Development of Learning Device based Ethnoscience for Heat Material in Kabupaten Tegal. Journal of Education and Learning (EduLearn), 12(3), 392. Google Scholar

Syawaludin, A., Gunarhadi, \& Rintayati, P. (2019). Development of augmented realitybased interactive multimedia to improve critical thinking skills in science learning. International Journal of Instruction, 12(4), 331-344. Google Scholar

Thiagarajan, \& Lawhon, D. (1976). Instructional development for training teachers of exceptional children: A sourcebook. Journal of School Psychology, 14(1), 75. Google Scholar

Wardika, I. W. G. (2020). Interaksi Model Pembelajaran Tandur Berbantuan Media. Paedagoria: Jurnal Kajian, Penelitian Dan Pengembangan Kependidikan, 6356(2), 99-105. https://doi.org/10.31764. Google Scholar

\section{Copyright holder:}

Firda Rosita, Hasan Mahfud dan Dwi Yuniasih Saputri (2021)

First publication right:

Journal Syntax Literate

This article is licensed under:

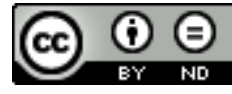

